\author{
Artículo científico \\ Volumen 32(1):34-44. Enero-abril, 2021 \\ e-ISSN 2215-3608, doi:10.15517/am.v32i1.43184 \\ https://www.revistas.ucr.ac.cr/index.php/agromeso
}

\title{
Caracterización multivariada de la eficiencia productivo-reproductiva y edad al primer parto en vacas Holstein ${ }^{1}$
}

\section{A multivariate characterization of productive-reproductive efficiency and age at first calving in Holstein cows}

\author{
Pablo Roberto Marini ${ }^{2}$, Pablo Biga ${ }^{2}$, Ricardo José Di-Masso ${ }^{3}$
}

1 Recepción: 29 de julio, 2020. Aceptación: 13 de octubre, 2020. Este trabajo formó parte del proyecto de investigación titulado: Utilización de indicadores de eficiencia biológica y económica para la evaluación de bovinos lecheros en sistemas a pastoreo Resol. CS №178/2018. Facultad de Ciencias Veterinarias - Universidad Nacional de Rosario.

2 Universidad Nacional de Rosario (UNR), Facultad de Ciencias Veterinarias y Carrera de Investigador Científico (CIC), Argentina. Ovidio Lagos y Ruta 33 CP (2170) Casilda Provincia de Santa Fe. pmarini@unr.edu.ar (autor para la correspondencia; https://orcid.org/0000-00030826-0387), pablo.biga@vas.com (https://orcid.org/0000-0002-0883-1509).

3 Centro Latinoamericano de Estudios de Problemáticas Lecheras (CLEPL). Ovidio Lagos y Ruta 33 CP (2170) Casilda Provincia de Santa Fe, Argentina.rjdimasso@gmail.com (https://orcid.org/0000-0003-0826-0387).

\section{Resumen}

Introducción. La evaluación de la eficiencia productiva debe estar acompañada por indicadores integrales para valorar el comportamiento de las vacas lecheras en los sistemas de pastoreo. Objetivo. Identificar en un rodeo de vacas lecheras Holstein agrupadas por su edad al primer parto, las de mayor eficiencia en sistemas de pastoreo, con base en una caracterización multivariada en indicadores productivos y reproductivos. Materiales y métodos. Se utilizaron datos retrospectivos de 1785 vacas primíparas de raza Holstein entre los años 1999-2016, en dos establecimientos comerciales pertenecientes a la empresa Los Ángeles - Argentina, las que se dividieron en tres grupos por su edad al primer parto: Grupo 1 - 750 días, Grupo 2 - 840 días y Grupo 3 - 1098 días. Las variables vida productiva total, producción total de leche, índice de leche e intervalo entre partos promedio se utilizaron asociadas a la edad al primer parto mediante la técnica multivariada de componentes principales. Resultados. No se observaron agrupamientos asociados al grupo de edad al primer parto. Los dos primeros componentes principales explicaron el $92,9 \%$ de la variancia total observada. Se pudo definir cuatro cuadrantes representando todas las combinaciones entre los valores positivos y negativos. La distribución de las vacas de los tres grupos en los cuatro cuadrantes resultó homogénea ( $\mathrm{x} 2=6,291 ; \mathrm{p}=0,391)$. La distribución por cuadrante, independientemente del Grupo de edad al primer parto fue de: Cuadrante I (52/150, 34,7 \%), Cuadrante II (42/150; 28,0 \%), Cuadrante III (28/150; 18,7 \%) y Cuadrante IV (28/150; $18,7 \%$ ). Conclusión. Las vacas ubicadas en el Cuadrante II (valores negativos de la CP1 y positivos de la CP2), fueron las eficientes al sistema de pastoreo, mostraron mayor longevidad con niveles productivos compatibles con las limitaciones del sistema y un eficiente comportamiento reproductivo.

Palabras clave: sistema de pastoreo, indicadores, longevidad, producción de leche, reproducción. 


\begin{abstract}
Introduction. The evaluation of productive efficiency must be accompanied by comprehensive indicators to assess the behavior of dairy cows in grazing systems. Objective. To identify in a herd of Holstein dairy cows grouped by age at first calving, those with the highest efficiency in grazing systems, based on a multivariate characterization of productive and reproductive indicators. Materials and methods. Retrospective data from 1785 primiparous cows of the Holstein breed, registered between the years 1999-2016 in two commercial establishments belonging to the Los Angeles-Argentina company, were used. Cows were categorized into three groups according to their age at first calving: Group 1 - 750 days, Group 2 - 840 days, and Group 3 - 1098 days. The variables total productive life, total milk production, milk index, and average calving interval were used associated with the age at first calving using the multivariate principal components technique. Results. No groupings associated with age group at first birth were observed. The two first principal components explained $92.9 \%$ of the total variance observed. It was possible to define four quadrants representing all the combinations between the positive and negative values. Cows distribution of the three groups in the four quadrants was homogeneous ( $\mathrm{x} 2=6.291 ; \mathrm{p}=0.391)$. The distribution per quadrant, regardless of the age group at first calving was: Quadrant I (52/150, $34.7 \%)$; Quadrant II (42/150, $28.0 \%)$; Quadrant III (28/150; $18.7 \%)$; Quadrant IV (28/150; $18.7 \%)$. Conclusion. Cows located in Quadrant II (negative values of $\mathrm{PC} 1$ and positive values of $\mathrm{PC} 2$ ), were efficient in the grazing system, showed greater longevity with productive levels compatible with the limitations of the system, and with an efficient reproductive behavior.
\end{abstract}

Keywords: grazing system, indicators, longevity, milk production, reproduction.

\title{
Introducción
}

Durante parte del siglo XX se planteó la necesidad de alcanzar una mayor producción individual de los animales con fines productivos, con el objetivo de lograr un aumento de la eficiencia y así satisfacer un mercado de consumo en crecimiento que exigía productos a bajo costo. Lo sucedido con las vacas lecheras en los últimos cincuenta años, representa un ejemplo en este sentido, en donde el mejoramiento se direccionó hacia un aumento de la producción individual de leche (Oltenacu \& Algers, 2005; Miglior et al., 2017).

En la actualidad, las principales causas de descarte de las vacas lecheras están relacionadas con los altos niveles de producción de leche y la baja eficiencia reproductiva, debido a los efectos directos de ambas sobre la rentabilidad y la viabilidad económica de los sistemas productivos (Bello et al., 2012). Estas dos causas, producción de leche y reproducción, son aspectos interconectados, en tanto los cambios en uno afectan la expresión del otro (Oltenacu \& Broom, 2010; Berry et al., 2016), y dada su vinculación con ambos caracteres, la edad al primer parto emerge como un punto de referencia a gestionar adecuadamente, a fin de lograr un mayor rendimiento económico y una vida productiva más larga (Do et al., 2013).

La producción individual de leche, si bien es la modalidad más difundida, no representa el indicador más acertado para operacionalizar una variable compleja como es la eficiencia productiva. Por lo tanto, la misma debería estar acompañada por otros indicadores que se constituyan en alternativas más integrales para valorar el comportamiento de las vacas lecheras en los sistemas de pastoreo. La utilización de este tipo de indicadores contribuiría a evitar la sobrevaloración de solo algunos caracteres involucrados en la identificación del biotipo más adecuado al sistema en donde se desempeñan productivamente los animales (Marini et al., 2017).

La búsqueda de mayor producción de leche, especialmente en el inicio de la lactancia, podría repercutir negativamente en la eficiencia reproductiva (König et al., 2008). Los bajos resultados reproductivos en los primeros ciclos luego de la liberación a servicio, obedecerían a un conjunto de factores, entre los que mencionan, el estrés 
por calor, la pérdida de condición corporal, patologías y concentraciones crecientes de progesterona durante el folículo pre-ovulatorio en desarrollo (Wiltbank et al., 2016). El progreso genético o la selección de animales para una mayor producción de leche, ha cambiado los perfiles endocrinos de las vacas, las concentraciones en sangre de somatotropina y prolactina han aumentado, mientras que la insulina ha disminuido (Bonczeck et al., 1988). Estos cambios hormonales y la mayor demanda de nutrientes para la producción de leche, asociados con los criterios de selección utilizados en los sistemas intensivos, tienen un impacto negativo en la reproducción de las vacas lecheras (Nebel \& McGilliard, 1993). El desequilibrio en la ingesta de energía tiene un impacto perjudicial en la actividad reproductiva de estos animales. La escasez de energía durante el período de crecimiento y en el período pre y posparto inhibe la aparición del celo y reduce la fertilidad en las hembras (Hileman et al., 1999).

Dentro de este contexto, el uso de procedimientos multivariados para la identificación de indicadores agregados es de mucha utilidad, porque posibilitan combinar múltiples datos procedentes de la investigación. El análisis de componentes principales (ACP) y el análisis factorial (AF) se pueden utilizar para resumir fenotipos multivariados complejos en un número menor de variables generadas a partir de diferentes combinaciones lineales de aquellas originalmente incorporadas al modelo, conservando la mayor variabilidad original posible y, además, permitiendo interpretar las asociaciones existentes entre las variables estudiadas (Kirkpatrick \& Meyer, 2004).

Las decisiones sobre la elección de animales para un determinado rasgo suelen hacerse intuitivamente, descuidando sus componentes y su asociación con otros rasgos. El análisis multivariado de componentes principales podría contribuir a la interpretación de las relaciones entre caracteres y, en consecuencia, a la toma de decisiones más acertadas especialmente en situaciones en la que no se pueden hacer evaluaciones genéticas (Kirkpatrick \& Meyer, 2004). En este sentido, resulta trascendente la descripción de las correlaciones fenotípicas entre rasgos reproductivos y productivos en vacas lecheras, a fin que los productores sean conscientes de las posibles implicaciones que podría tener la selección de su rodeo solo destacando la producción (Roso \& Fries, 1995).

El objetivo de este trabajo fue identificar en un rodeo de vacas lecheras Holstein agrupadas por su edad al primer parto, las de mayor eficiencia en sistemas a pastoreo, con base en una caracterización multivariada en indicadores productivos y reproductivos.

\section{Materiales y métodos}

Se utilizaron datos retrospectivos correspondientes a las lactancias de 1785 vacas primíparas de raza Holstein, biotipo americano-canadiense, recolectados entre los años 1999-2016 en dos establecimientos comerciales pertenecientes a la empresa Los Ángeles, ubicados en la localidad de Villa Elisa, departamento Colón, provincia de Entre Ríos, Argentina: Establecimiento I ( $\left.32^{\circ} 04^{\prime} 21,0^{\prime \prime} \mathrm{S}, 58^{\circ} 38^{\prime} 13,8^{\prime \prime} \mathrm{O}\right)$ y Establecimiento II $\left(32^{\circ} 07^{\prime} 53,7^{\prime \prime} \mathrm{S}\right.$, $\left.58^{\circ} 36^{\prime 2} 2,7^{\prime \prime} \mathrm{O}\right)$. Ambos sitios se caracterizan por:

- Utilizar vacas de la raza Holstein biotipo americano - canadiense, Jersey y sus cruzas.

- La alimentación era básicamente pastoreo (praderas de alfalfa) con suplementación (grano de maíz, silo de maíz y heno de alfalfa), suministrada en diferentes proporciones, de acuerdo con la disponibilidad estacional de las praderas de alfalfa.

- Las salas de ordeño eran en espinas de pescado.

- Contaban con control lechero oficial.

- Estaban libres de brucelosis y tuberculosis y con control de leptospirosis, rinotraqueitis infecciosa bovina y diarrea viral bovina.

- Contaban con identificación electrónica en todos los animales, detección de celo por pintura, bloqueo de los servicios por dos meses para evitar partos en enero y febrero. Control ginecológico semanal. Llevaban registros en el sistema DairyComp. 
- Desde hace veinte años, en ambos se inseminaba artificialmente, con semen de toros probados, mediante detección de celo natural, uso de prostaglandina y/o inseminación artificial a tiempo fijo.

- En el lapso indicado, todas las vacas se sometieron al mismo manejo y se utilizaron similares instalaciones de ordeño.

A los efectos del análisis solo se incluyeron aquellos registros correspondientes a las vacas con información desde su nacimiento hasta la fecha de su descarte o muerte, que hubieran tenido al menos un segundo parto. Este último criterio se incluyó para asegurar que la comparación no resultara viciada por la presencia de vacas con una primera lactancia fallida.

Para lograr mayor uniformidad en la base de datos, del total de vacas que cumplían con los criterios de inclusión se descartaron aquellas con menos de 671 días o más de 1098 días al primer parto, o con una primera lactancia menor a 150 días y un intervalo primer-segundo parto menor a 310 días.

Del total de vacas que cumplieron los criterios de inclusión, se identificaron tres grupos de acuerdo con la edad de primer pasto, a saber, Grupo 1: edad al primer parto 750 días (24 meses), Grupo 2: edad al primer parto 840 días (27 meses) y Grupo 3: edad al primer parto 1098 días (32 meses); se eligieron al azar cincuenta integrantes de cada uno de dichos grupos.

Cada una de las vacas pertenecientes a cada uno de los tres grupos, se caracterizó en función de los valores de los siguientes indicadores productivos y reproductivos:

\section{Indicadores productivos}

Edad al primer parto (EPP): (fecha del primer parto - fecha de nacimiento), en días.

Vida productiva total (VPT): (fecha de descarte o muerte - fecha de nacimiento), edad (días) desde el nacimiento al descarte o muerte.

Producción leche total (PLT): $\Sigma$ litros de leche por lactancia terminada, litros totales de leche producidos en su vida productiva.

Índice de leche (IL): total para su vida productiva, il: PLT/VPT (Marini y Oyarzabal, 2002a, b).

\section{Indicador reproductivo}

Intervalo parto-parto promedio (IPPp): (edad (días) de descarte o muerte - edad (días) al primer parto) / ( $\mathrm{n}^{\circ}$ de partos - 1).

\section{Análisis estadístico}

Con el fin de investigar posibles agrupamientos asimilables a los tres grupos predefinidos por su edad al primer parto, con diferente aporte de los cuatro indicadores (VPT, PLT, IL e IPPp), se aplicó la técnica multivariada de componentes principales (Carrasco y Hernán, 1993). A los efectos del análisis, los componentes principales generados en el análisis multivariado, correspondientes a cada animal, fueron tratados como nuevas variables aleatorias.

Los valores individuales del primero (CP1) y del segundo componente principal (CP2) generados por el programa para cada vaca, se graficaron en un sistema de coordenadas cartesianas ortogonal (abscisa y ordenada, respectivamente), lo que permitió definir cuatro cuadrantes que se numeraron de I a IV en sentido inverso a las agujas del reloj, comenzando por el superior derecho. Se identificaron los animales ubicados en cada cuadrante, lo que permitió definir para los componentes utilizados cuatro grupos de vacas. La asociación entre el grupo de EPP $\mathrm{y}$ el cuadrante se evaluó con una prueba $\mathrm{x}^{2}$ de independencia.

El efecto del cuadrante de pertenencia sobre cada una de las variables productivas y reproductivas mencionadas, se evaluó con un análisis de la variancia a un criterio de clasificación (cuadrante), seguido de la prueba de comparaciones múltiples de Bonferroni. 


\section{Resultados}

Los componentes principales 1 y 2, en conjunto, contuvieron el 92,9\% de la variancia total observada, lo que indicó la conveniencia de considerar solo a estos para la interpretación de las relaciones conjuntas entre los indicadores productivos y el indicador reproductivo.

El primer componente principal (CP1) explicó el 67,9 \% de la variancia total y se correlacionó en forma negativa y significativa con VPT ( $r=-0,929 ; \mathrm{p}<0,0001)$, PLT ( $r=-0,996 ; \mathrm{p}<0,0001)$, IL ( $r=-0,925 ; \mathrm{p}<0,0001)$ y no mostró asociación con IPPp ( $r=0,082 ; \mathrm{p}=0,321)$. Su vector propio (eigenvector) fue: $\mathrm{CP} 1=-0,5638 \mathrm{VPT}-0,6040$ PLT - 0,5612 IL + 0,0495 IPPp. En consecuencia, este componente se denominó eficiencia productiva. A mayor valor de la misma corresponde menor longitud de vida productiva, menor producción de leche y menor índice de leche. Estas vacas presentaron mayor intervalo entre partos.

El segundo componente principal (CP2) explicó el 25,0 \% de la variancia total y se correlacionó en forma negativa y no significativa con VPT $(r=-0,075 ; p=0,364)$, PLT $(r=-0,021 ; p=0,797)$, en forma positiva y no significativa con IL $(r=0,010 ; p=0,905)$ y en forma negativa y significativa con IPPp $(r=-0,996 ; p=<0,0001)$. El vector propio (eigenvector) fue: CP2 = - 0,0747 VPT - 0,0211 PLT + 0,0098 IL - 0,9969 IPPp. El componente se denominó eficiencia reproductiva. A mayor valor de PC2 correspondieron vacas con menor intervalo parto-parto promedio independientemente de su longitud de vida productiva, de su producción total de leche y de su índice de leche.

No se observaron diferencias estadísticamente significativas de $\mathrm{CP} 1$ entre categorías $(\mathrm{F}=2,234 ; \mathrm{P}=0,111)$, si bien se constató una tendencia a valores negativos del componente (es decir, vacas con mayor longitud de vida productiva y, por ende, mayor producción total de leche y mayor índice de leche, independientemente de su intervalo parto-parto promedio) con el aumento de la edad al primer parto. Con base en esta tendencia y, debido a la variabilidad observada en los valores de este componente, la misma no pudo asociarse con un agrupamiento significativo vinculado a la categoría de edad al primer parto de las vacas.

No se observaron diferencias estadísticamente significativas entre categorías $(F=2,150 ; p=0,120)$ en el caso de CP2. Las vacas del Grupo II (edad al primer parto 840 días - 27 meses), con una edad intermedia al primer parto, presentaron, en promedio, valores negativos del componente, indicativos de una tendencia a un mayor intervalo parto-parto promedio, independientemente de la longitud de su vida productiva, de su producción total de leche y de su índice de leche. Pese a dicha tendencia y, al igual que en el caso de CP1, debido a la variabilidad observada en los valores de CP2, la misma no pudo asociarse con un agrupamiento significativo vinculado a la categoría de edad al primer parto de las vacas.

De la representación conjunta de los valores de CP1 (abscisa) y CP2 (ordenada): (a) las vacas del Cuadrante I, con valores positivos de ambos componentes, presentaron menor longitud de vida productiva, menor producción total de leche, menor índice de leche (CP1) y menor intervalo parto-parto promedio (CP2); (b) el Cuadrante II, con valores negativos de $\mathrm{CP} 1$ y positivos de $\mathrm{CP} 2$, fueron vacas con mayor longitud de vida productiva, mayor producción total de leche, mayor índice de leche (CP1) y menor intervalo parto-parto promedio (CP2). Las vacas del Cuadrante III, con valores negativos de ambos componentes, fueron vacas con mayor longitud de vida productiva, mayor producción total de leche, mayor índice de leche (CP1) y mayor intervalo parto-parto promedio (CP2). Las vacas del Cuadrante $\mathrm{IV}$, con valores positivos de $\mathrm{CP} 1$ y negativos de $\mathrm{CP} 2$, fueron vacas con menor longitud de vida productiva, menor producción total de leche, menor índice de leche (CP1) y mayor intervalo parto-parto promedio (CP2).

La distribución de las vacas de los tres grupos en los cuatro cuadrantes resultó homogénea $\left(\mathrm{x}^{2}=6,291 ; \mathrm{P}=\right.$ 0,391). La distribución por cuadrante, independientemente del crupo de edad al primer parto fue de: Cuadrante I (52/150, 34,7 \%); Cuadrante II (42/150; 28,0 \%); Cuadrante III (28/150; 18,7 \%); Cuadrante IV (28/150; 18,7 \%).

Para ninguno de los tres grupos se rechazó la hipótesis de distribución uniforme en los cuatro cuadrantes [25\% de representantes en cada uno: Grupo I $\left(\mathrm{x}^{2}=3,539 ; \mathrm{P}=0,316\right)$, Grupo II $\left(\mathrm{x}^{2}=0,161 ; \mathrm{P}=0,984\right)$ y Grupo III $\left(\mathrm{x}^{2}=5,092 ; \mathrm{P}=\right.$ 0,165)], pero la mayor aproximación a una distribución igualitaria se observó en el Grupo II, mientras que en los dos 
grupos restantes los animales tendieron a agruparse en los cuadrantes superiores correspondientes a valores positivos de CP2 (menor intervalo parto-parto promedio) y, en particular, en el Cuadrante I que asocia el menor intervalo parto-parto (deseable) a menores valores de longitud de vida productiva, producción total de leche e índice de leche (no deseable).

El Cuadro 1 resume los valores correspondientes a las vacas pertenecientes al Grupo I. A nivel productivo, aquellas ubicadas en los Cuadrantes II y III presentaron la vida productiva total (VPT) más larga, los valores más elevados de producción, tanto de producción de litros totales (PLT) como de índice de leche (IL) con diferencias significativas $(\mathrm{p} \leq 0,05)$, aunque solo las del Cuadrante II mostraron los valores más bajos de intervalo partoparto promedio (IPPp). Las vacas pertenecientes a los Cuadrantes I y IV tuvieron los menores valores de vida productiva total, producción de litros totales e índice de leche; sin embargo, en el intervalo parto-parto promedio se diferenciaron, teniendo el menor valor las vacas del Cuadrante I, al igual que las vacas del Cuadrante II con diferencias significativas $(\mathrm{p} \leq 0,05)$.

Cuadro 1. Indicadores productivos y reproductivos (media aritmética \pm error estándar) de vacas raza Holstein biotipo AmericanoCanadiense del Grupo I (edad al primer parto 750 días - 24 meses) discriminadas por el cuadrante de pertenencia en el plano cartesiano definido por los valores de los dos primeros componentes principales. Villa Elisa, departamento Colón, provincia de Entre Ríos, Argentina. 1999-2016.

Table 1. Productive and reproductive indicators (arithmetic mean \pm standard error) of American-Canadian biotype Holstein breed cows Group I (age at first calving 750 days - 24 months) discriminated by their location quadrant on the Cartesian plane defined by the two first principal components values. Villa Elisa, Colon department, Entre Rios province, Argentina. 1999-2016.

\begin{tabular}{|c|c|c|c|c|c|c|}
\hline & $\begin{array}{c}\text { C I } \\
n=18\end{array}$ & $\begin{array}{c}\text { C II } \\
n=14\end{array}$ & $\begin{array}{l}\text { C III } \\
n=6\end{array}$ & $\begin{array}{c}\text { C IV } \\
n=12\end{array}$ & $\mathbf{F}$ & p \\
\hline CP1 & $\begin{array}{l}1,1100 \mathrm{a} \\
\pm 0,1892\end{array}$ & $\begin{array}{c}-0,8907 \mathrm{~b} \\
\pm 0,1749\end{array}$ & $\begin{array}{c}-1,3920 b \\
\pm 0,4089\end{array}$ & $\begin{array}{l}1,6230 \mathrm{a} \\
\pm 0,1765\end{array}$ & 41,61 & $<0,0001$ \\
\hline $\mathrm{CP} 2$ & $\begin{array}{l}0,4962 \mathrm{a} \\
\pm 0,0775\end{array}$ & $\begin{array}{l}0,6089 \mathrm{a} \\
\pm 0,0705\end{array}$ & $\begin{array}{c}-0,4812 \mathrm{~b} \\
\pm 0,1853\end{array}$ & $\begin{array}{c}-0,9443 \mathrm{~b} \\
\pm 0,2649\end{array}$ & 25,29 & $<0,0001$ \\
\hline VPT & $\begin{array}{c}1699 \text { a } \\
\pm 61,7\end{array}$ & $\begin{array}{c}2434 \mathrm{~b} \\
\pm 65,0\end{array}$ & $\begin{array}{l}2593 \mathrm{~b} \\
\pm 140,2\end{array}$ & $\begin{array}{l}1651 \mathrm{a} \\
\pm 66,2\end{array}$ & 38,71 & $<0,0001$ \\
\hline PLT & $\begin{array}{c}19374 \mathrm{a} \\
\pm 1370\end{array}$ & $\begin{array}{c}36192 \mathrm{~b} \\
\pm 1628\end{array}$ & $\begin{array}{c}41767 \mathrm{~b} \\
\pm 4025\end{array}$ & $\begin{array}{c}16002 \mathrm{a} \\
\pm 1275\end{array}$ & 43,06 & $<0,0001$ \\
\hline IL & $\begin{array}{l}11,21 \mathrm{a} \\
\pm 0,576\end{array}$ & $\begin{array}{l}14,89 \mathrm{~b} \\
\pm 0,560\end{array}$ & $\begin{array}{l}15,95 \mathrm{~b} \\
\pm 0,754\end{array}$ & $\begin{array}{l}9,60 \mathrm{a} \\
\pm 0,529\end{array}$ & 20,32 & $<0,0001$ \\
\hline IPPp & $\begin{array}{l}480,8 \mathrm{a} \\
\pm 16,64\end{array}$ & $\begin{array}{l}432,2 \mathrm{a} \\
\pm 16,35\end{array}$ & $\begin{array}{l}667,3 \mathrm{~b} \\
\pm 42,25\end{array}$ & $\begin{array}{l}800,8 \mathrm{~b} \\
\pm 57,72\end{array}$ & 27,02 & $<0,0001$ \\
\hline
\end{tabular}

CP1: componente principal 1, CP2: componente principal 2, VPT: vida productiva total en días, PLT: producción de leche total en litros, IL: índice de leche en litros, IPPp: intervalo parto-parto promedio en días, C I: cuadrante I, C II: cuadrante II, C III: cuadrante III, C IV: cuadrante IV, F: estadístico F de Snedecor, valor p: valor de significancia / CP1: main component 1, CP2: main component 2, VPT: total productive life in days, PLT: total milk production in liters, IL: milk index in liters, IPPp: average calving to calving interval in days, C I: Quadrant I, C II: Quadrant II, C III: Quadrant III, C IV: Quadrant IV, F: Snedecor's F statistics, p: significance value.

El Cuadro 2 resume los valores correspondientes a las vacas pertenecientes al Grupo II. A nivel productivo, aquellas ubicadas en los Cuadrantes II y III presentaron la vida productiva total (VPT) más alta, los valores más elevados de producción tanto de producción de litros totales (PLT) como de índice de leche (IL) con diferencias 
Cuadro 2. Indicadores productivos y reproductivos (media aritmética \pm error estándar) de las vacas raza Holstein biotipo AmericanoCanadiense del Grupo II (edad al primer parto 840 días - 27 meses) discriminadas por el cuadrante de pertenencia en el plano cartesiano definido por los valores de las dos primeras componentes principales. Villa Elisa, departamento Colón, provincia de Entre Ríos, Argentina.1999-2016.

Table 2. Productive and reproductive indicators (arithmetic mean \pm standard error) of American-Canadian biotype Holstein breed cows Group II (age at first calving 840 days -27 months) discriminated by their location quadrant on the Cartesian plane defined by the two first principal components values. Villa Elisa, Colon department, Entre Rios province, Argentina. 1999-2016.

\begin{tabular}{lcccccc}
\hline & $\mathbf{C} \mathbf{~}$ & $\mathbf{C}$ II & $\mathbf{C}$ III & $\mathbf{C}$ IV & $\mathbf{F}$ & P \\
$\mathbf{n = 1 4}$ & $\mathbf{n = 1 3}$ & $\mathbf{n = 1 2}$ & $\mathbf{n}=\mathbf{1 1}$ & & \\
\hline PC1 & $1,3890 \mathrm{a}$ & $-1,5340 \mathrm{~b}$ & $-1,4920 \mathrm{~b}$ & $1,4000 \mathrm{a}$ & 47,53 & $<0,0001$ \\
& $\pm 0,2594$ & $\pm 0,2187$ & $\pm 0,2813$ & $\pm 0,1895$ & & \\
PC2 & $0,6855 \mathrm{a}$ & $0,5404 \mathrm{a}$ & $-0,9147 \mathrm{~b}$ & $-1,5620 \mathrm{~b}$ & 23,12 & $<0,0001$ \\
& $\pm 0,0989$ & $\pm 0,0913$ & $\pm 0,2538$ & $\pm 0,4045$ & & \\
VPT & $1681 \mathrm{a}$ & $2672 \mathrm{~b}$ & $2735 \mathrm{~b}$ & $1774 \mathrm{a}$ & 27,83 & $<0,0001$ \\
& $\pm 94,4$ & $\pm 87,3$ & $\pm 151,2$ & $\pm 86,8$ & & \\
PLT & $17356 \mathrm{a}$ & $42482 \mathrm{~b}$ & $42703 \mathrm{~b}$ & $17850 \mathrm{a}$ & 46,76 & $<0,0001$ \\
& \pm 1808 & \pm 2129 & \pm 2754 & \pm 1543 & & \\
IL & $10,03 \mathrm{a}$ & $15,85 \mathrm{~b}$ & $15,60 \mathrm{~b}$ & $9,96 \mathrm{a}$ & 30,90 & $<0,0001$ \\
& $\pm 0,787$ & $\pm 0,492$ & $\pm 0,387$ & $\pm 0,552$ & & \\
IPPp & $439,5 \mathrm{a}$ & $438,9 \mathrm{a}$ & $758,6 \mathrm{~b}$ & $933,5 \mathrm{~b}$ & 24,17 & $<0,0001$ \\
& $\pm 20,83$ & $\pm 18,72$ & $\pm 57,15$ & $\pm 86,70$ & & \\
\hline
\end{tabular}

CP1: componente principal 1, CP2: componente principal 2, VPT: vida productiva total en días, PLT: producción de leche total en litros, IL: índice de leche en litros, IPPp: intervalo parto-parto promedio en días, C I: cuadrante I, C II: cuadrante II, C III: cuadrante III, C IV: cuadrante IV, F: estadístico F de Snedecor, valor p: valor de significancia / CP1: main component 1, CP2: main component 2, VPT: total productive life in days, PLT: total milk production in liters, IL: milk índex in liters, IPPp: average calving to calving interval in days, C I: Quadrant I, C II: Quadrant II, C III: Quadrant III, C IV: Quadrant IV, F: Snedecor's F statistics, p: significance value.

significativas $(\mathrm{p} \leq 0,05)$, aunque solo el Cuadrante II mostró los valores más bajos de intervalo parto-parto promedio (IPPp). Las vacas pertenecientes a los Cuadrantes I y IV tuvieron los menores valores de vida productiva total, producción de litros totales e índice de leche; sin embargo, en el intervalo parto-parto promedio se diferenciaron, teniendo el menor valor las vacas del Cuadrante I, al igual que las vacas del Cuadrante II con diferencias significativas $(\mathrm{p} \leq 0,05)$.

El Cuadro 3 resume los valores correspondientes a las vacas pertenecientes al Grupo III. A nivel productivo, aquellas ubicadas en los Cuadrantes II y III presentaron la vida productiva total (VPT) más alta, los valores más elevados de producción, tanto de producción de litros totales (PLT) como de índice de leche (IL) con diferencias significativas $(\mathrm{p} \leq 0,05)$, aunque solo el Cuadrante II mostró los valores más bajos de intervalo parto-parto promedio (IPPp). Las vacas pertenecientes a los Cuadrantes I y IV tuvieron los menores valores de vida productiva total, producción de litros totales e índice de leche; sin embargo, se diferenciaron en el intervalo parto-parto promedio, el menor valor lo tuvieron las vacas en el Cuadrante I, al igual que las vacas del Cuadrante II, con diferencias significativas $(\mathrm{p} \leq 0,05)$. 
Cuadro 3. Indicadores productivos y reproductivos (media aritmética \pm error estándar) de las vacas raza Holstein biotipo AmericanoCanadiense del Grupo II (edad al primer parto 1098 días - 32 meses) discriminadas por el cuadrante de pertenencia en el plano cartesiano definido por los valores de las dos primeras componentes principales. Villa Elisa, departamento Colón, provincia de Entre Ríos, Argentina.1999-2016.

Table 3. Productive and reproductive indicators (arithmetic mean \pm standard error) of American-Canadian biotype Holstein breed cows Group II (age at first calving 1098 days - 32 months) discriminated by their location quadrant on the Cartesian plane defined by the two first principal components values. Villa Elisa, Colon department, Entre Rios province, Argentina. 1999-2016.

\begin{tabular}{|c|c|c|c|c|c|c|}
\hline & $\begin{array}{c}C \text { I } \\
n=20\end{array}$ & $\begin{array}{c}\text { C II } \\
n=15\end{array}$ & $\begin{array}{c}\text { C III } \\
n=10\end{array}$ & $\begin{array}{l}\text { C IV } \\
n=5\end{array}$ & $\mathbf{F}$ & $\mathbf{P}$ \\
\hline $\mathrm{CP} 1$ & $\begin{array}{l}1,1390 \mathrm{a} \\
\pm 0,2095\end{array}$ & $\begin{array}{c}-1,8340 \mathrm{~b} \\
\pm 0,2808\end{array}$ & $\begin{array}{c}-1,7510 \mathrm{~b} \\
\pm 0,3969\end{array}$ & $\begin{array}{l}1,3170 \mathrm{a} \\
\pm 0,3423\end{array}$ & 34,16 & $<0,0001$ \\
\hline $\mathrm{CP} 2$ & $\begin{array}{l}0,4962 \mathrm{a} \\
\pm 0,0775\end{array}$ & $\begin{array}{l}0,6089 \text { a } \\
\pm 0,0705\end{array}$ & $\begin{array}{c}-0,4812 b \\
\pm 0,1853\end{array}$ & $\begin{array}{c}-0,9443 \mathrm{~b} \\
\pm 0,2649\end{array}$ & 25,29 & $<0,0001$ \\
\hline VPT & $\begin{array}{c}1910 \mathrm{a} \\
\pm 89,5\end{array}$ & $\begin{array}{l}2793 \mathrm{~b} \\
\pm 108,8\end{array}$ & $\begin{array}{l}2878 \mathrm{~b} \\
\pm 150,3\end{array}$ & $\begin{array}{l}1903 \mathrm{a} \\
\pm 111,8\end{array}$ & 20,76 & $<0,0001$ \\
\hline PLT & $\begin{array}{c}19129 \mathrm{a} \\
\pm 1513\end{array}$ & $\begin{array}{c}45306 \mathrm{~b} \\
\pm 2864\end{array}$ & $\begin{array}{c}45439 \mathrm{~b} \\
\pm 3924\end{array}$ & $\begin{array}{c}18192 \mathrm{a} \\
\pm 2686\end{array}$ & 32,46 & $<0,0001$ \\
\hline IL & $\begin{array}{r}9,73 \mathrm{a} \\
\pm 0,489\end{array}$ & $\begin{array}{l}16,28 \mathrm{~b} \\
\pm 0,888\end{array}$ & $\begin{array}{l}15,57 \mathrm{~b} \\
\pm 0,580\end{array}$ & $\begin{array}{c}9,40 \mathrm{a} \\
\pm 0,907\end{array}$ & 25,50 & $<0,0001$ \\
\hline IPPp & $\begin{array}{l}434,2 \mathrm{a} \\
\pm 17,09\end{array}$ & $\begin{array}{l}453,6 \text { a } \\
\pm 15,37\end{array}$ & $\begin{array}{l}716,6 \mathrm{~b} \\
\pm 80,14\end{array}$ & $\begin{array}{l}786,5 \mathrm{~b} \\
\pm 55,48\end{array}$ & 18,17 & $<0,0001$ \\
\hline
\end{tabular}

CP1: componente principal 1, CP2: componente principal 2, VPT: vida productiva total en días, PLT: producción de leche total en litros, IL: índice de leche en litros, IPPp: intervalo parto-parto promedio en días, C I: cuadrante I, C II: cuadrante II, C III: cuadrante III, C IV: cuadrante IV, F: estadístico F de Snedecor, valor p: valor de significancia / CP1: main component 1, CP2: main component 2, VPT: total productive life in days, PLT: total milk production in liters, IL: milk índex in liters, IPPp: average calving to calving interval in days, C I: Quadrant I, C II: Quadrant II, C III: Quadrant III, C IV: Quadrant IV, F: Snedecor's F statistics, p: significance value.

\section{Discusión}

Los componentes generados en el análisis multivariado pueden ser considerados como nuevas variables aleatorias susceptibles de ser interpretadas y nominadas con el agregado que, por no estar correlacionadas entre sí, explicaron porciones independientes de la variancia total observada en la población. Los dos primeros componentes, si bien en diferente proporción, explicaron el $92 \%$ de la variabilidad total. Los signos y significados de las correlaciones entre los valores de cada componente y los indicadores que intervinieron en su cálculo, permitieron identificar diferentes asociaciones que pusieron en evidencia la complejidad de las relaciones entre esos caracteres, en tanto, el primer componente se vinculó en forma negativa con VPT, PLT e IL y positivamente con IPPP, mientras que el segundo lo hizo en forma positiva con VPT y PLT y negativa con IL y IPPP.

La interpretación dada a la combinación de caracteres en cada componente (eficiencia productiva y eficiencia reproductiva) para el primero y el segundo, respectivamente, posibilitó definir cuatro nuevas categorías de vacas según su localización en los cuadrantes generados a partir de la representación gráfica de ambos.

Las vacas pertenecientes al Cuadrante II combinaron de manera favorable los indicadores utilizados, mayor longevidad, mayor producción acumulada, mayor producción combinada y mejor eficiencia reproductiva. El Cuadrante II, al igual que ocurrió en el caso de los tres cuadrantes restantes, incluyó animales de los tres grupos de edad al primer parto, lo que puso en evidencia la variabilidad propia de la población utilizada y la ausencia de asociación entre la edad a la primera parición y el desempeño posterior bajo las condiciones del sistema en estudio. 
Las vacas pertenecientes al Cuadrante III presentaron, al igual que las vacas del Cuadrante II, mayor longevidad, producción acumulada y producción combinada, pero presentan menor eficiencia reproductiva. Las razones del deterioro reproductivo resultan difíciles de explicar, en tanto que con niveles de producción muy similares a las ubicadas en el Cuadrante II, presentaron un intervalo parto-parto promedio muy superior.

Esta evidencia indica que la asociación producción-reproducción no es necesariamente estricta y que, muy probablemente, subyacen en la misma factores genéticos, cuya caracterización sería trascendente en el diseño de estrategias de mejoramiento para estos ambientes. Esto podría explicar también, el por qué las vacas del Cuadrante III se comportaron de esta manera, a diferencia de las del Cuadrante II.

A una menor edad al primer parto disminuye el costo de la cría, permite adelantar el ingreso a la vida productiva, aumenta la ganancia genética anual y eleva el promedio de vida productiva del animal (Singh et al., 2013; Singh et al., 2017). Sin embargo, también la inclusión de rasgos de longevidad como criterio de selección aumentaría la rentabilidad de los rebaños lecheros (Honarvar et al., 2010). Los rasgos utilizados en este trabajo como la vida productiva total, la producción de leche total, el índice de leche como indicador combinado y el intervalo parto-parto promedio reflejarían la salud (longevidad), la adaptación (índice de leche), la fertilidad y no solo el nivel de producción (Ratwan et al., 2017).

Los resultados demostraron que la existencia de variabilidad genética dentro de las vacas analizadas, les permitió expresar su potencial productivo, frente a las limitaciones existentes del ambiente, con mayor o menor impacto sobre los aspectos reproductivos en un claro ejemplo de correlación genotipo-ambiente. Podría suponerse, que los sistemas a pastoreo, al presentar menores niveles de estrés para las vacas (Grandin, 2000), permitirían una mayor longevidad, si bien no se observó en este caso, en parte debido al antagonismo entre la producción y reproducción (Frioni et al., 2016) asociado a los límites (ambientales y manejo) propios que impone el sistema de pastoreo, juega un rol fundamental.

\section{Conclusiones}

El plano definido por el primer y el segundo componente principal, mostró que las vacas pertenecientes al Cuadrante II, independientemente de su edad al primer parto, presentaron una mayor eficiencia bajo el sistema de pastoreo con suplementación, lo que se tradujo en una mayor longevidad (mayor permanencia en el sistema) con niveles productivos compatibles con las limitaciones del mismo y con un eficiente comportamiento reproductivo.

\section{Referencias}

Bello, N. M., Stevenson, J. S., \& Tempelman, R. J. (2012). Invited review: milk production and reproductive performance: modern interdisciplinary insights into an enduringaxiom. Journal of Dairy Science, 95, 5461-5475. https://doi. org/10.3168/jds.2012-5564

Bonczeck, R. R., Young, C. W., Wheaton, J. E., \& Miller, K. P. (1988). Responses of somatotropin, insulin, prolactin, and thyroxine to selection for milk yield in Holsteins. Journal of Dairy Science, 71, 2470-2479.

Berry, D. P., Friggens, N. C., Lucy, M., \& Roche, J. R. (2016). Milk production and fertility in cattle. Annual Review of Animal Biosciences, 4, 269-290. https://doi.org/10.1146/annurev-animal-021815-111406

Carrasco, J. L., \& Hernán, M. A. (1993). Estadística multivariante en las ciencias de la vida. Editorial Ciencia. 
Do, C., Wasana, N., Cho, K., Choi, Y., Choi, T., Park, B., \& Lee, B. (2013). The Effect of Age at First Calving and Calving Interval on Productive Life and Lifetime Profit in Korean Holsteins. Asian Australasian Journal of Animal Science, 26(11), 1511-1517. http://dx.doi.org/10.5713/ajas.2013.13105

Frioni, N., Urioste, J. I., Aguilar I., \& Rovere G. (2016). Genetic parameters of days open, milk, fat and protein yield of Uruguayan Holstein on pasture systems. Journal of Basic \& Applied Genetics, 27(Suppl. 1), 190. https://sag.org.ar/ jbag/wp-content/uploads/2020/01/V.XXVIII_2016_Suppl1_19092016.pdf

Grandin, T. (2000). Principles of animal behavior for the handling of bovines and other herbivorous in extensive conditions. In G. Temple (Ed.), Livestock Handling and Transport (2nd ed., pp. 63-85). CABI Publishing.

Hileman, S. M., Lubbers, L. S., Jansen, H. T., \& Lehman, M. N. (1999). Changes in hypothalamic estrogen receptor-containing cell numbers in response to feed restriction in the female lamb. Neuroendocrinology, 69, 430-437.

Honarvar, M., Nejati-Javaremi, A., Miraei-Ashtiani, S. R., \& Banadaki, M. (2010). Effect of length of productive life on genetic trend of milk production and profitability: A simulation study. African Journal of Biotechnology, 9(20), 3000-3010. http://www.academicjournals.org/AJB

Kirkpatrick, M., \& Meyer, K. (2004). Direct estimation of genetic principal components: simplified analysis of complex phenotypes. Genetics, 168, 2295-2306. https://doi.org/10.1534/genetics.104.029181

König, S., Chang, Y. M., Borstel, U. U. V., Gianola, D., \& Simianer, H. (2008). Genetic and phenotypic relationships among milk urea nitrogen, fertility, and milk yield in Holstein cows. Journal of Dairy Science, 91, 4372-4382. https://doi. org/10.3168/jds.2008-1236

Marini, P. R., \& Oyarzabal, M. I. (2002a). Patrones de producción en vacas lecheras. 1 Componentes de la producción y sus características según nivel de producción. Revista Argentina Producción Animal, 22(1), 29-46.

Marini, P. R., \& Oyarzabal, M. I. (2002b). Patrones de producción en vacas lecheras. 2 Descripción de la vaca promedio y estimación de los ingresos según categorías de producción. Revista Argentina Producción Animal, 22(1), 47-60.

Marini, P. R., Castro, R., Frana, E., \& Di Masso, R. J. (2017). Multivariate characterization of biological efficiency in dairy cows in grazing systems. Sustainable Agriculture Research, 6(4), 83-92. https://doi.orgi.orgi.org/10.5539/sar.v6n4p83sar

Miglior, F., Fleming, A., Malchiodi, F., Brito, L. F., Martin, P., \& Baes, C. F. (2017). A 100-Year Review: Identification and genetic selection of economically important traits in dairy cattle. Journal of Dairy Science, 100, 10251-10271. https:// doi.org/10.3168/jds.2017-12968

Nebel, R. L., \& McGilliard, M. L. (1993). Interactions of high milk yield and reproductive performance in dairy cows. Journal of Dairy Science, 76, 3257-3268. https://doi.org/10.3168/jds.S0022-0302(93)77662-6

Oltenacu, P. A., \& Algers, B. (2005). Selection for increased production and the welfare of dairy cows: Are new breeding goals needed? Ambio, 34(4-5), 311-315.

Oltenacu, P. A., \& Broom, D. M. (2010). The impact of genetic selection for increased milk yield on the welfare of dairy cows. Animal Welfare, 19, 39-49.

Ratwan, P., Mandal, A., Kumar, M., \& Chakravarty, A. K. (2017). Genetic analysis of milk production efficiency traits in Jersey crossbred cattle. Indian Journal of Animal Research, 51(4), 644-647. https://doi.org/10.18805/ijar.7076

Roso, V. M., \& Fries, L.A. (1995). Componentes principais em bovinos da raça PolledHereford à desmama e sobreano. Revista Brasileira de Zootecnia, 24, 728-735. 
Singh, J., Singh, V. K., Kumar, A. Y., \& Kumar, A. J. (2017). Effect of genetic and non-genetic factors on age at first calving in Sahiwal cattle. Indian Journal of Animal Research, 51(4), 635-639. https://doi.org/10.18805/ijar.8425

Singh, S., Rana, Z. S., Pander, B. L., Dhaka S. S., \& Kumar, R. (2013). Prediction of phenotypic value of lifetime performance from early lactation traits in Hariana cattle. Indian Journal of Animal Research, 47(4), 352-355. https://arccjournals. com/journal/indian-journal-of-animal-research/ARCC156

Wiltbank, M. C., Baez, G. M., García-Guerra, A., Toledo, M. Z., Monteiro, P. L. J., Melo, L. F., Ochoa, J. C., Santos, J. E. P., \& Sartori, R. (2016). Pivotal periods for pregnancy loss during the first trimester of gestation in lactating dairy cows. Theriogenology, 86, 239-253. https://doi.org/10.1016/j.theriogenology.2016.04.037 